\title{
Percepção ambiental de alunos do ensino fundamental da zona rural do Município de Paulista, Paraíba, Brasil
}

Environmental perception of students of fundamental education in the rural area of the City of Paulista, Paraíba, Brazil

Percepción ambiental de estudiantes de educación fundamental en el área rural del Municipio de Paulista, Paraíba, Brasil

\section{Resumo}

Diante de uma escola inserida no campo é elementar a compreensão da percepção ambiental dos estudantes em relação ao meio ambiente. Objetivou-se neste trabalho identificar a percepção sobre o meio ambiente de alunos dos anos finais do ensino fundamental do município de Paulista-PB. A pesquisa teve como objeto de estudo os estudantes de duas escolas da zona rural do município de Paulista-PB no período de março a junho de 2021, com a participação de 136 alunos. A pesquisa foi descritiva qualitativa e obteve os dados através de formulário relacionando a temática do meio ambiente. Diante da análise deste estudo registrou-se que $89 \%$ dos alunos de ambas escolas são conhecedoras da definição do termo sobre o meio ambiente, mas, sentem dificuldades em se entenderem como integrante do meio ambiente. Foi identificado uma carência dos alunos em perceberem temas ambientais de forma interdisciplinar, porém, ficou evidenciado uma positiva participação da escola no processo de ações e projetos com a temática ambiental, contribuindo para o desenvolvimento crítico dos alunos perante aos problemas ambientais.

Palavras-chave: Educação ambiental; Meio ambiente; Escola.

\begin{abstract}
Through a school inserted in the field, the understanding of the students' environmental perception in relation to the environment is elementary. The objective of this work was to identify the perception about the environment of students in the final years of elementary school in the city of Paulista-PB. The research had as object of study students from two rural schools in the city of Paulista-PB, from March to June 2021, with the participation of 136 students. The research was descriptive and qualitative and obtained data through a form relating to the theme of the environment. In view of the analysis of this study, it was recorded that $89 \%$ of students from both schools are aware of the definition of the term about the environment, but, find it difficult to perceive themselves as an integral part of the environment. A lack of students in perceiving environmental issues in an interdisciplinary way was identified, however, a positive participation of the school in the process of actions and projects with the environmental theme was evidenced, contributing to the critical development of students in the face of environmental problems.
\end{abstract}

Keywords: Environmental education; Environment; School.

\section{Resumen}

A través de una escuela insertada en el campo, la comprensión de la percepción ambiental de los estudiantes en relación con el medio ambiente es elemental. El objetivo de este trabajo fue identificar la percepción sobre el entorno de los estudiantes de los últimos años de la escuela primaria en la ciudad de Paulista-PB. La investigación tuvo como objeto de estudio estudiantes de dos escuelas rurales de la ciudad de Paulista-PB, de marzo a junio de 2021, con la participación de 136 estudiantes. La investigación fue descriptiva y cualitativa y obtuvo datos a través de un formulario relacionado con la temática del medio ambiente. A la vista del análisis de este estudio, se registró que el $89 \%$ de los alumnos de 
ambas escuelas conocen la definición del término sobre medio ambiente, pero tienen dificultades para entenderse como parte del medio. Se identificó una falta de estudiantes en la percepción de los temas ambientales de manera interdisciplinaria, sin embargo, se evidenció una participación positiva de la escuela en el proceso de acciones y proyectos con el tema ambiental, contribuyendo al desarrollo crítico de los estudiantes ante los problemas ambientales.

Palabras clave: Educación ambiental; Medio ambiente; Colegio.

\section{Introdução}

O termo "percepção" no dicionário português tem o significado de ação ou efeito de perceber, de compreender o sentido de algo por meio das sensações ou da inteligência. De forma semelhante Chauí (2002), explica que a percepção é uma comunicação, uma interpretação e um reconhecimento baseado nas relações entre os órgãos sensoriais do corpo e o mundo. Já Leff (2010) designa a percepção ambiental na perspectiva do contexto vivido, quando afirma que todo o conhecimento adquirido durante a história humana tem estado sujeito ao contexto cultural, ecológico e geográfico, em que se baseia a historicidade social.

No espaço escolar é possível desenvolver a percepção ambiental através de conhecimentos e informações que estimulem os estudantes a serem responsáveis por suas condutas, dessa maneira é possível atingir uma maior estruturação e compreensão sobre o tema, tornando os alunos capazes de criarem uma percepção de integração com a natureza (Sousa \& Fernandes, 2015).

É a partir dos estudos da percepção ambiental que a Educação Ambiental induz a adoção de novas condutas voltadas ao uso racional dos recursos ambientais e exercita a participação das pessoas na percepção necessária para identificar atores e transformá-los, cada ser humano é dotado de percepções únicas que fornecem dados necessários para agregação de ideias de acordo com suas representações no planeta (Costa \& Maroti, 2009).

A escola é o local lócus privilegiado para o desenvolvimento da sensibilização ambiental, a Educação Ambiental deve ser trabalhada de forma interdisciplinar e assim tornará os alunos capazes de refletirem sobre problemáticas ambientais atuais, contribuindo para condutas ecológicas com o meio ambiente e a disseminação do conhecimento fora do ambiente escolar devido ao processo de socialização (Leite, Leite \& Leite, 2017).

A interação alunos com a natureza, e em especial os alunos de escolas do campo, interfere diretamente na forma de percepção que os mesmos apresentam sobre o conhecimento ambiental, as ações de conscientização fornecem um estímulo de construção crítica e sensibilização do local onde vivem, fornecendo estímulos para um comprometimento com o meio ambiente (Oliveira et al., 2013).

A Educação Ambiental tem caráter decisivo em relação a diminuição dos problemas ambientais causados pelo homem, caracteriza-se por desempenhar uma participação ativa através do desenvolvimento da sensibilidade sobre as necessidades para a conservação da natureza. É muito importante construir uma Educação Ambiental abrangente a todos os níveis educacionais, especialmente no ensino básico por existir uma maior facilidade em conscientização dos alunos enquanto jovens (Medeiros et al., 2011).

Santos e Vasconcelos (2017) ressaltam que cada indivíduo reage, percebe e responde as diferentes ações sobre o ambiente em que vive. Nesse entendimento, Faggionato (2011) relata que as formas de estudar a percepção ambiental devem ser variadas em seus instrumentos de pesquisas, incluindo: questionários, entrevistas, mapas mentais, desenhos, representações fotográficas entre outros, de forma a captar os saberes, vivências que integram os indivíduos.

Os estudos de percepção do meio ambiente são relevantes para o desenvolvimento crítico quanto ao uso correto dos recursos naturais, pode gerar uma interação direta com a natureza, além de cultivar um pensamento analista (Oliveira et al., 2013).

O foco das pesquisas em estudos de percepção ambiental deve se ocupar muito além do aspecto discursivo e esvaziado de sentidos. Deve se dirigir aos modos de viver e de se relacionar com a natureza, o lugar habitado e a coletividade que se pode ancorar uma postura sensível e pró-ativa e uma discursividade enraizada, crítica, capaz de gerar o comprometimento das pessoas, 
focos das metas da educação ambiental (Marin, 2008).

Visando suprir a necessidade de se conhecer a tomada de consciência, mais conhecida como a percepção ambiental, quanto a temática "meio ambiente" no âmbito escolar da zona rural e podendo contribuir para um debate à cerca das interrelações entre homem-ambiente e a atuação da escola sobre essas temáticas, fornecendo meios para o diagnóstico e desenvolvimento da Educação Ambiental para a realidade das escolas rurais.

Este estudo teve como objetivo identificar a percepção sobre o meio ambiente de alunos dos anos finais do ensino fundamental da zona rural do município de Paulista-PB.

\section{Metodologia}

\subsection{Caracterização da área de estudo}

O município de Paulista está localizado no estado da Paraíba, região nordeste do Brasil (Figura1). Estende-se por uma área de aproximadamente $577,379 \mathrm{~km}^{2}$ e a população estimada em 2020 era cerca de 12.379 pessoas com densidade demográfica de 20,43 habitantes por $\mathrm{km}^{2}$. O clima é caracterizado como tropical semiárido com baixos índices pluviométricos (IBGE, 2010).

Figura 1 - Localização do município de Paulista no estado da Paraíba.

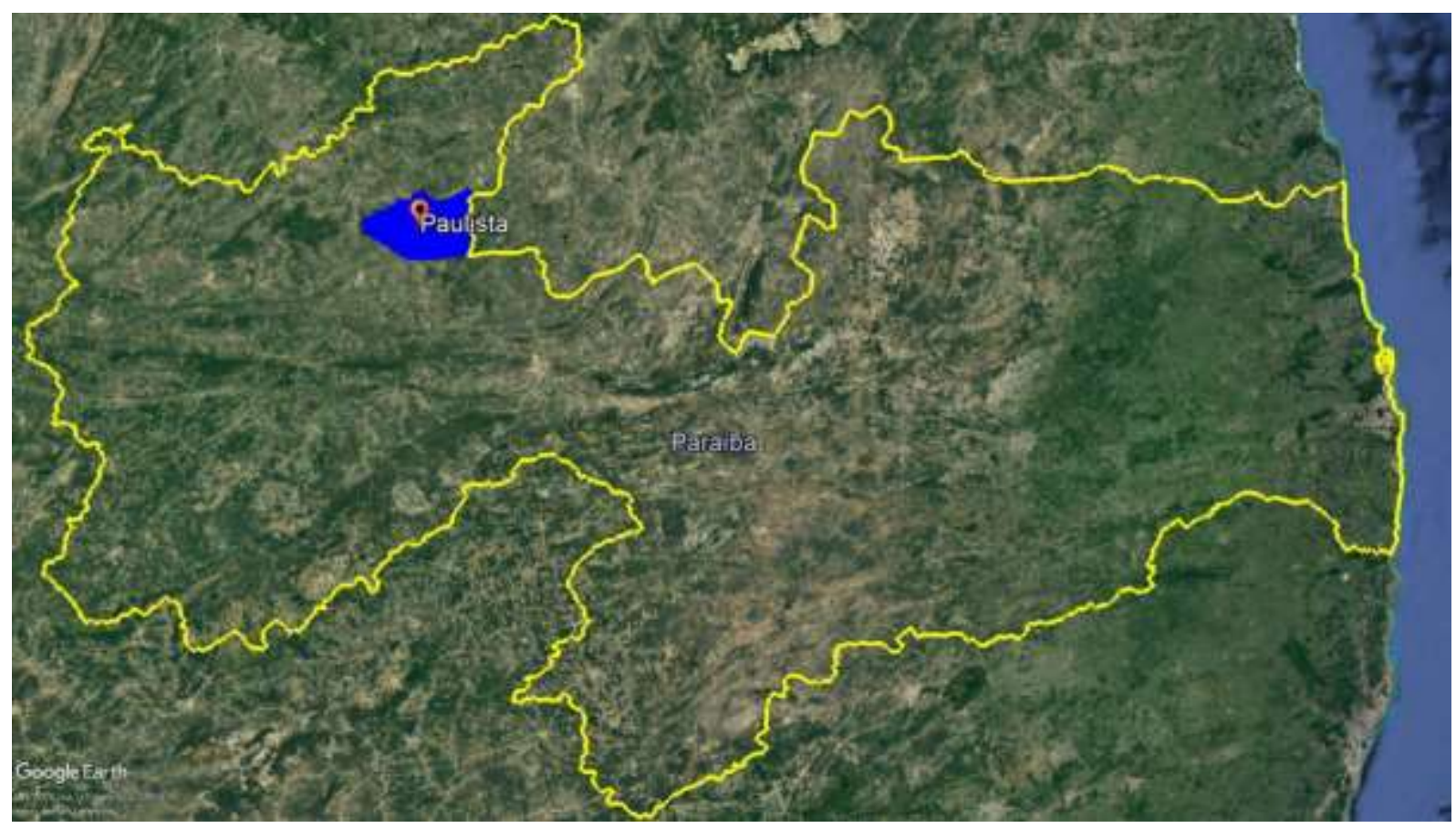

Fonte: Google Earth Pro.

O estudo foi realizado em duas escolas públicas do município de Paulista/PB (Figura 2), a Escola Municipal de Ensino Fundamental Otacílio Tomé (EMEFOT), localizada no sítio André e a Escola Municipal de Ensino Fundamental Pedro Marques de Medeiros (EMEFPMM) localizada no distrito Ipueira. Ambas situadas na zona rural do município com aproximadamente 5 km de distância da cidade de Paulista-PB. 
Figura 2 - Escolas do município de Paulista onde foi realizado o estudo. (A) Escola Municipal de Ensino Fundamental Otacílio Tomé. (B) Escola Municipal de Ensino Fundamental Pedro Marques de Medeiros.

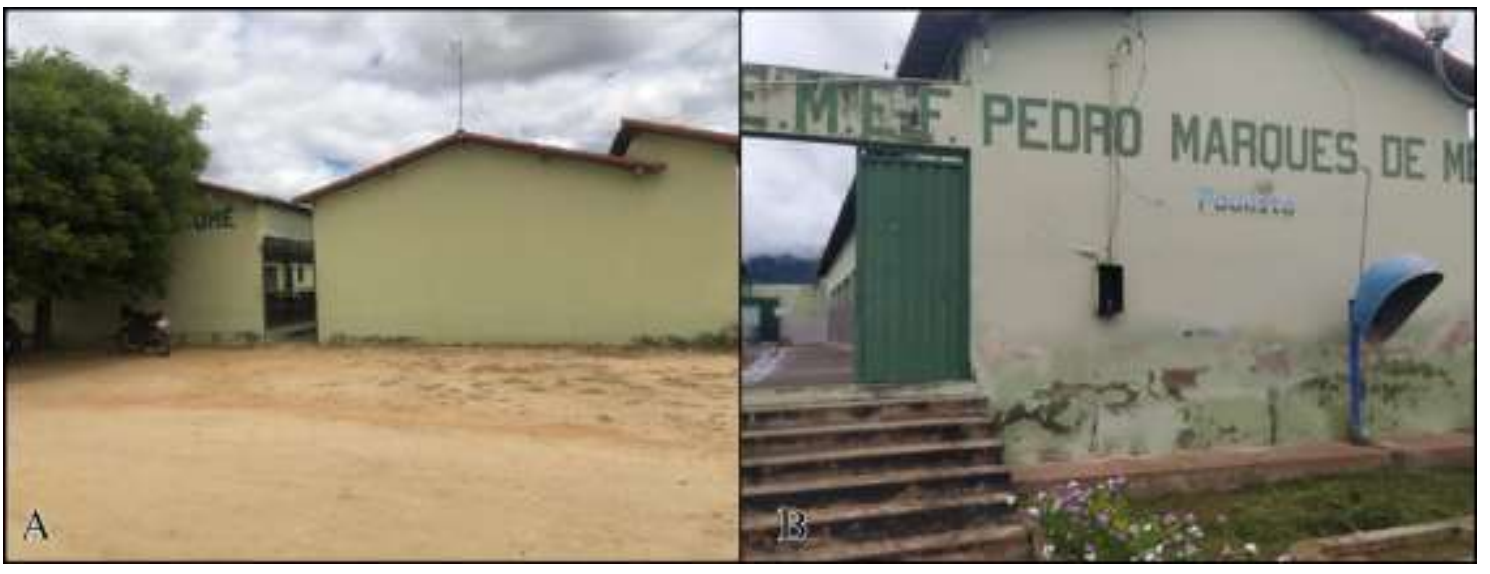

Fonte: Dados da pesquisa (2021).

\subsection{Coleta dos dados}

Foi realizada uma pesquisa exploratória a fim de identificar os conhecimentos e percepções ambientais dos alunos das referidas escolas, os dados foram obtidos através de um formulário online disponibilizado pelo software Google Forms, o formulário abrangeu 10 questões com as seguintes temáticas: reconhecimento de conceitos básicos e pertencimento ao meio ambiente, problemáticas rurais, reconhecimento de preservação da natureza e reconhecimento sobre atuação da escola sobre as temáticas ambientais.

A abordagem metodológica deste trabalho foi quali-quantitativa do tipo descritiva. Segundo Appolinário (2006), esse modelo de pesquisa tem como propósito entender e interpretar os fenômenos estudados e não generalizá-los. Em contrapartida, Prodanov e De Freitas (2013) relata que na pesquisa quantitativa, todas as informações coletadas são representadas através de números que podem ser analisadas por recursos de técnicas estatísticas.

O formulário foi aplicado a todos os alunos do sexto ao nono ano do ensino fundamental. A EMEFOT apresentou um total de 63 alunos, e na EMEFPM contabilizou-se 120 estudantes matriculados. Levando em consideração a quantidade de alunos foi adotada a técnica desenvolvida por Vasconcelos (2005) e utilizada por Pereira, Farrapeira e Pinto (2006), adaptando-a para este estudo.

Foram criadas três categorias que serviram de indicadores de avaliação das respostas expressivas: 1", "satisfatórias", quando as respostas foram consideradas íntegras e os alunos demonstraram ter amplo conhecimento do tema, $2^{\mathrm{a}}$, “parcialmente satisfatórias" quando as respostas demonstraram que os alunos foram detentores de um conhecimento mínimo sobre o tema, $3^{\mathrm{a}}$, “insatisfatórias" quando as respostas demonstraram que os alunos não souberam nada sobre o tema ou deixaram perguntas do formulário sem resposta.

Os dados coletados foram dispostos sob formato matricial no software Microsoft Excel 2013, onde foram tratados e representados na forma de gráficos e tabelas.

\section{Resultados e Discussão}

Foram analisados 136 formulários, 45 referentes aos alunos da Escola Municipal do Ensino Fundamental Otacílio Tomé (EMEFOT) e 91 formulários referente aos alunos da Escola Municipal do Ensino Fundamental Pedro Marques de Medeiros (EMEFPMM). 
Em relação ao gênero da população trabalhada, na EMEFOT, 47\% $(\mathrm{n}=21)$ dos alunos são do gênero masculino, 53\% ( $n=24)$ são do gênero feminino. Na EMEFPMM, 37\% $(n=34)$ dos alunos são do gênero masculino e 63\% (n = 57) são do gênero feminino.

Para as respostas de cunho afirmativo das perguntas 1, 2, 3, 6, 9 e 10 do formulário, foram gerados percentuais que estão apresentados no Gráfico 1.

Gráfico 1 - Percentual das respostas afirmativas dos alunos referente as perguntas 1, 2, 3, 6, 9 e 10 do formulário.

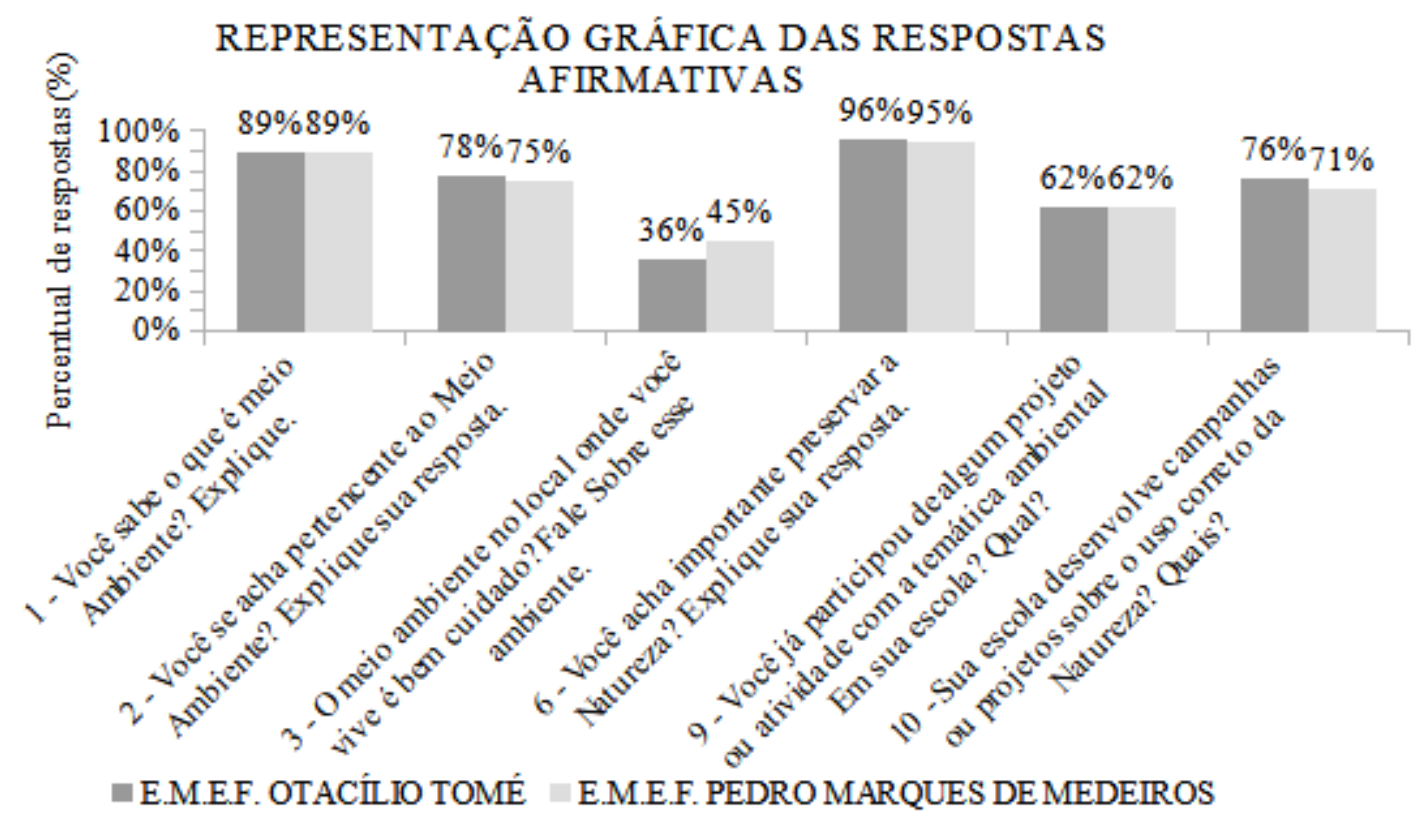

Fonte: Dados da pesquisa.

Na primeira pergunta os alunos foram indagados se sabiam o que era meio ambiente, dos alunos da EMEFOT, 40 afirmaram compreender o tema e 5 não sabiam, na EMEFPMM, 81 alunos afirmaram contra 7 que não sabiam, 3 alunos não responderam à pergunta. A maioria dos alunos demonstraram conhecer o termo de forma correta tendo as respostas classificadas como "satisfatórias" em ambas escolas.

Em relação à pergunta 2 onde questionou se o aluno se achava pertencente ao meio ambiente e pediu para que eles explicassem sua resposta, obteve-se os seguintes resultados: 35 estudantes da EMEFOT afirmaram e 6 negaram pertencer ao meio ambiente, 4 não responderam. Já na EMEFPMM, 68 alunos afirmaram e 20 negaram, 3 não responderam à pergunta. Mesmo afirmando pertencimento ao meio ambiente, a maioria das respostas descritivas dos alunos demonstraram que existe uma carência perceptiva como parte integrante ao meio ambiente, tendo a maioria das respostas classificadas como "parcialmente satisfatórias".

Assim temos o papel primordial da escola para direcionar a relação homem e meio ambiente voltada de forma harmoniosa, e consciente. Valendo-se do entendimento de Guimarães (1995), historicamente o homem, de maneira demasiada, foi explorando o meio ambiente para fins diversos, em especial o econômico, numa visão meramente exploratória e antropocêntrica, renegando assim seu papel de coparticipe/integrante desse meio.

Resultados semelhantes à primeira e segunda questão foram encontrados no trabalho de Gomes, Santos e Aparecida (2018) em uma unidade escolar no estado do Piauí, 98,3\% dos alunos afirmaram saber o significado de meio ambiente, no entanto 
é relatado que mesmo $73 \%$ dos alunos afirmarem pertencer do meio ambiente $26,7 \%$ ainda enfrentam dificuldades em se reconhecer como parte integrante dele.

O conceito de meio ambiente está inserido por lei federal no 6.938 como "o conjunto de condições, leis, influências e interações de ordem física, química e biológica, que permite, abriga e rege a vida em todas as suas formas" (Brasil, 1981).

Gonçalves (1999) apresenta que educação ambiental deve ser realizada como uma "metodologia de ação", de forma a tirar o estudante da posição de mero espectador da realidade que o cerca para colocá-lo como um protagonista da realidade, permitindo-lhe desenvolver o pensamento consciente, reflexivo e crítico.

Para a terceira pergunta do questionário onde os alunos teriam que declarar se o ambiente onde vivem é preservado foram obtidos os seguintes resultados: na EMEFOT e EMEFPMM respectivamente: 16 e 41 alunos disseram que o local onde vivem recebe cuidados, contra 24 e 47 alunos que negaram, 5 e 3 alunos não responderam. Ainda nessa interrogação, os alunos poderiam descrever o ambiente, porém, predominou a não reposta, impossibilitando maiores análises.

Ratificamos que o espaço escolar é um ambiente propício o desenvolvimento de ações voltadas à conscientização dos alunos para o meio ambiente por meio da Educação Ambiental, que tem favorecido o desenvolvimento de condições para uma coexistência harmoniosa e o despertar para novas ideias e princípios sobre o meio ambiente e assim contribuir para o estabelecimento de um equilíbrio no meio natural, estimulando o despertar dos alunos para o ambiente ao seu redor e propagando conhecimento para a sociedade (Medeiros, Ribeiro \& Ferreira, 2011).

O sexto item questionava aos estudantes se eles achavam importante preservar a natureza, a expressiva maioria disse "Sim" em ambas as escolas. Esse cenário vem ao encontro do pensamento de Viégas e Guimarães (2004), os quais consideram que o desenvolvimento dos aspectos cognitivos de crianças e adolescentes facilita o entendimento para a importância da preservação ambiental. Ainda conforme os citados autores, a nova geração traz consigo uma maior consciência ambiental, eles compreendem a importância, porém, mesmo com a disseminação da educação ambiental os problemas ambientais são desafiantes. Hoje temos o mundo mais degradado do que a trinta anos atrás.

Na nona pergunta do formulário, quando questionados se já haviam participado de algum projeto ou atividade com a temática ambiental, $62 \%$ em ambas as escolas afirmaram positivamente.

De forma diferente desta pesquisa, o estudo de Wollmann e Braibante (2013) apontou que 36\% dos alunos afirmaram ter participado de projetos e ações sobre o meio ambiente, e $64 \%$ disseram nunca ter participado.

A décima pergunta do formulário questionou aos alunos se na escola onde estudam desenvolve campanhas e projetos sobre o uso sustentável da natureza, na EMEFOT 34 e na EMEFPMM 65 dos estudantes responderam afirmando o desenvolvimento de tais ações.

Os percentuais encontrados nas escolas deste estudo tiveram semelhanças aos dados obtidos por Gregorini e Missirian (2009) onde 100\% dos alunos afirmaram que a escola desenvolve a temática ambiental, e os autores exprimem que a escola deve organizar temáticas de ensino que proporcione aos alunos oportunidades de percepção dos problemas e capacidade para conduzir ações de soluções aos problemas do meio ambiente.

De acordo com Costa (2001), o termo Protagonismo Juvenil é a participação ativa e construtiva do jovem no ambiente escolar e de sua comunidade envolvendo atividades direcionadas a problemas reais, atuando como não passivo como apregoava a concepção tradicional de ensino.

Quando questionados na quarta pergunta sobre qual ambiente de sua localidade deveria receber mais cuidados, os alunos citaram alguns exemplos, porém, o "rio" foi o mais lembrado, 16 alunos da EMEFOT o citaram tendo como percentual 36\%, 20 alunos da EMEFPMM também o destacaram tendo o percentual de 22\% (Gráfico 2). 
Gráfico 2 - Percentual das respostas dos alunos referente à quarta pergunta do formulário.

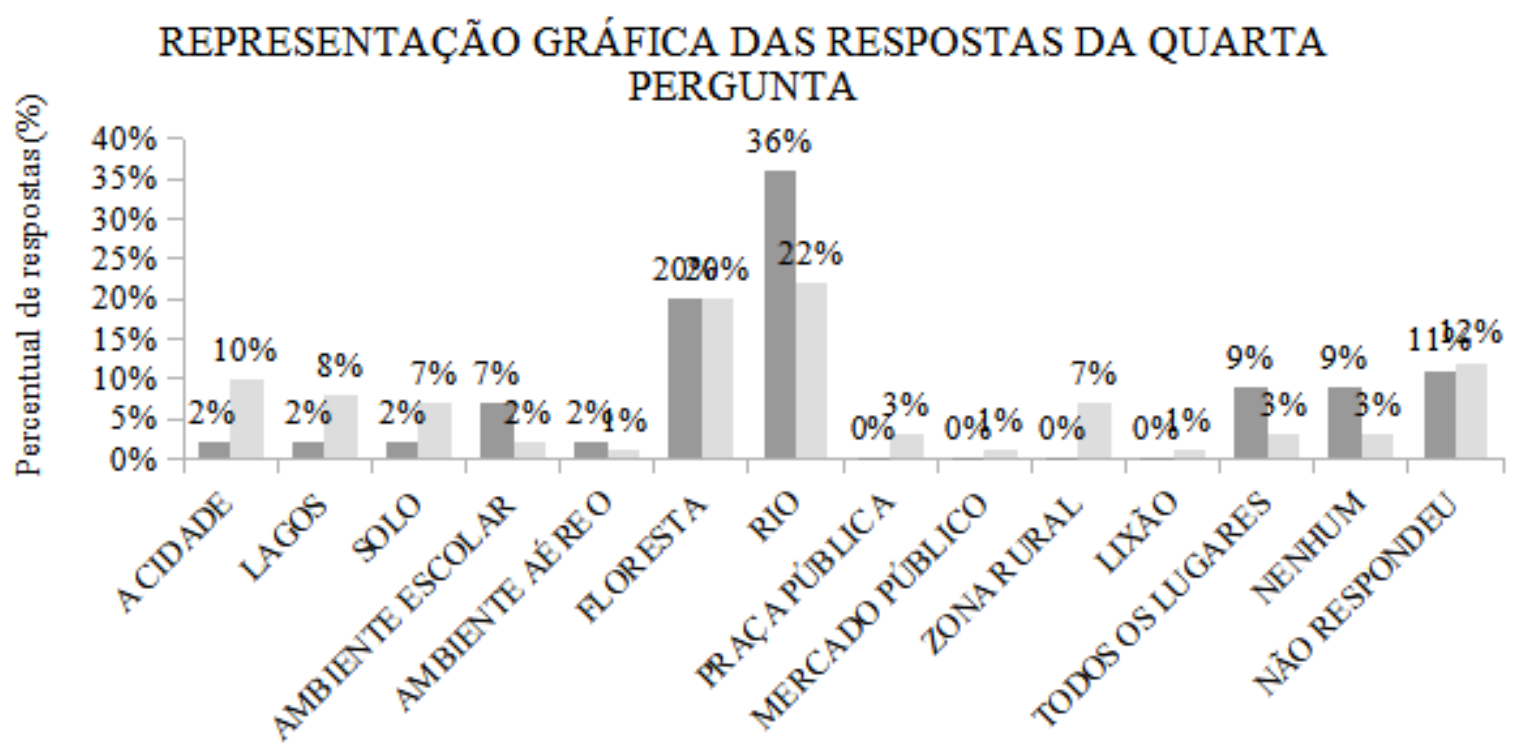

E.M.E.F. OTACÍIIO TOMÉ $\quad$ E.M.E.F. PEDRO MARQUES DE MEDEIROS

Fonte: Dados da pesquisa.

Lima (2017) salienta a importância da compreensão da história local pelos estudantes, desta maneira é possível o entendimento das problemáticas que os circundam e vivenciam na sociedade ou localidade onde moram, evitando assim que os mesmos tenham dificuldade para contextualizar os eventos posteriores que venham afetá-los do decorrer do tempo.

$\mathrm{O}$ questionamento feito aos alunos na quinta pergunta era referente aos problemas ambientais que ocorrem em sua localidade. 40 alunos da EMEFOT citaram 66 exemplos, na EMEFPMM 84 estudantes citaram 132 exemplos, com isso o percentual gerado faz referência ao número de vezes em que o termo foi lembrado pelos estudantes, o termo "Poluição" obteve os maiores índices uma vez que 30 alunos da EMEFOT e 71 da EMEFPMM fizeram referência a ele, resultando em 45\% e 54\% respectivamente (Gráfico 3). 
Gráfico 3 - Percentual das respostas dos alunos referente a quinta pergunta do formulário.

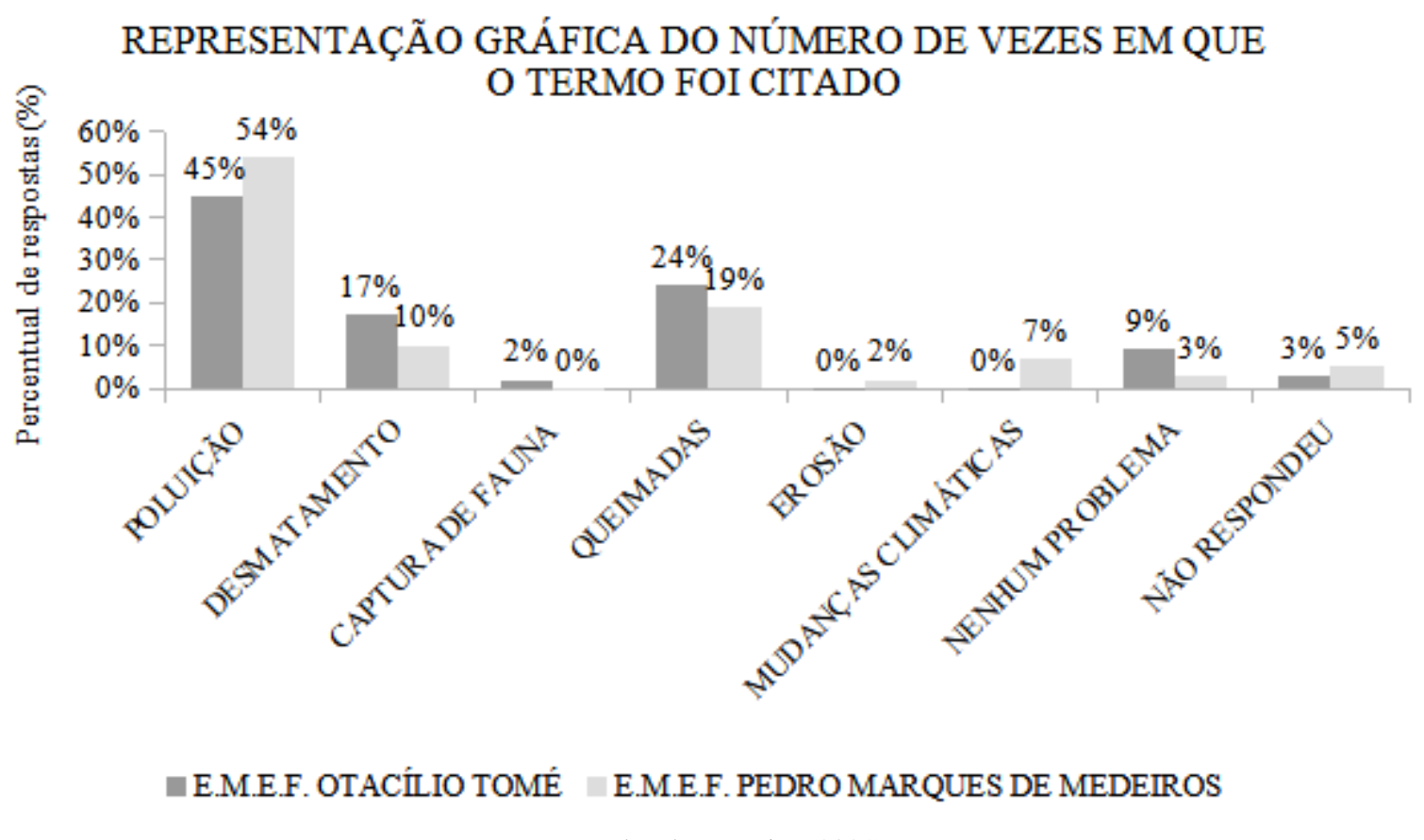

Fonte: Dados da pesquisa (2021).

De forma semelhante Castoldi, Bernardi e Polinarsk (2009) obtiveram resultados que corroboram com essa pesquisa, a maior parte dos alunos também citaram "poluição", "desmatamento", "queimadas", "alterações climáticas”. O autor defende que os exemplos citados pelos alunos são abordados diretamente em meios de comunicação e utilizados em livros didáticos como forma de exemplificação dos assuntos sobre o meio ambiente e dessa forma reflete na visão crítica dos estudantes sobre os problemas ambientais. Retirando dos alunos o destacamento de problemáticas ao seu entorno para sentir tanto, parte do contexto, quanto da colaboração da solução.

Na sétima pergunta do formulário, os alunos foram questionados sobre como eles contribuíam para a preservação da natureza, 41 alunos da EMEFOT e 85 estudantes da EMEFPMM responderam, a medida mais citada foi o ato de "não poluir", obtendo percentual de 53\% na EMEFOT e 51\% na EMEFPMM (Gráfico 4). 
Gráfico 4 - Percentual das respostas dos alunos referente à sétima pergunta do formulário.

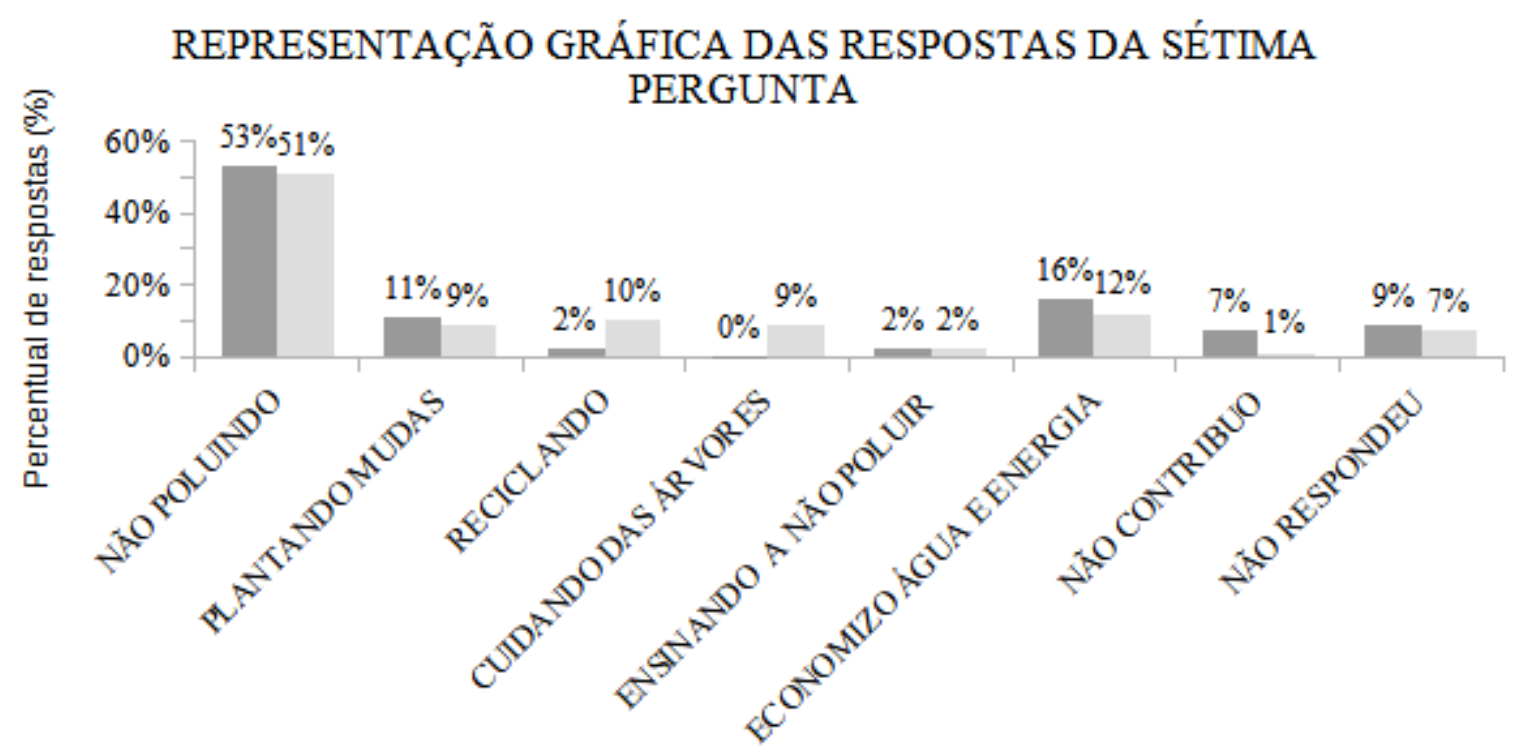

-E.M.E.F. OTACÍIIO TOMÉ E.M.E.F.PEDRO MARQUES DE MEDEIROS

Fonte: Dados da pesquisa.

Resultados semelhantes foram encontrados por Gregorini e Missirian (2009) quanto as medidas adotadas para cuidar do meio ambiente e foi apontado para a problemática o ato de "não poluir", seguindo de "cuidar das árvores" (plantando e preservando-as). Vemos aqui que a resposta do problema e solução foram coerentes, como que se sendo de fato problemática e soluções que se aproximam de seu entorno da sociedade.

Ainda na mesma pergunta alguns alunos citaram quem também deveria contribuir para a preservação da natureza, $31 \%$ $(n=14)$ dos alunos da EMEFOT e 38\% $(n=35)$ da EMEFPMM afirmaram que "Todos deveriam colaborar".

Segundo França (2006), quando o termo "todos nós" é citado, pode haver um indicativo de que o informador esteja deixando de ser atuante nos processos reais ao seu redor pois esse termo acaba sendo tratado de forma ampla e não designa especificamente um agente que deveria ter um papel atuante para resolver os problemas ambientais na sociedade.

A oitava pergunta fazia menção as disciplinas escolares onde os alunos tiveram que responder quais delas abordavam temas ambientais. 40 alunos da EMEFOT citaram 76 disciplinas, na EMEFPMM 76 alunos citaram 130, o percentual foi realizado pelo número de vezes em que o termo foi citado, as disciplinas de "ciências" e "geografia" foram as que tiveram maiores percentuais em ambas escolas com índices de $46 \%$ e $34 \%$ na EMEFOT e 50\% e 21\% na EMEFPMM respectivamente (Gráfico 5). 
Gráfico 5 - Percentual das respostas dos alunos referente à oitava pergunta do formulário.

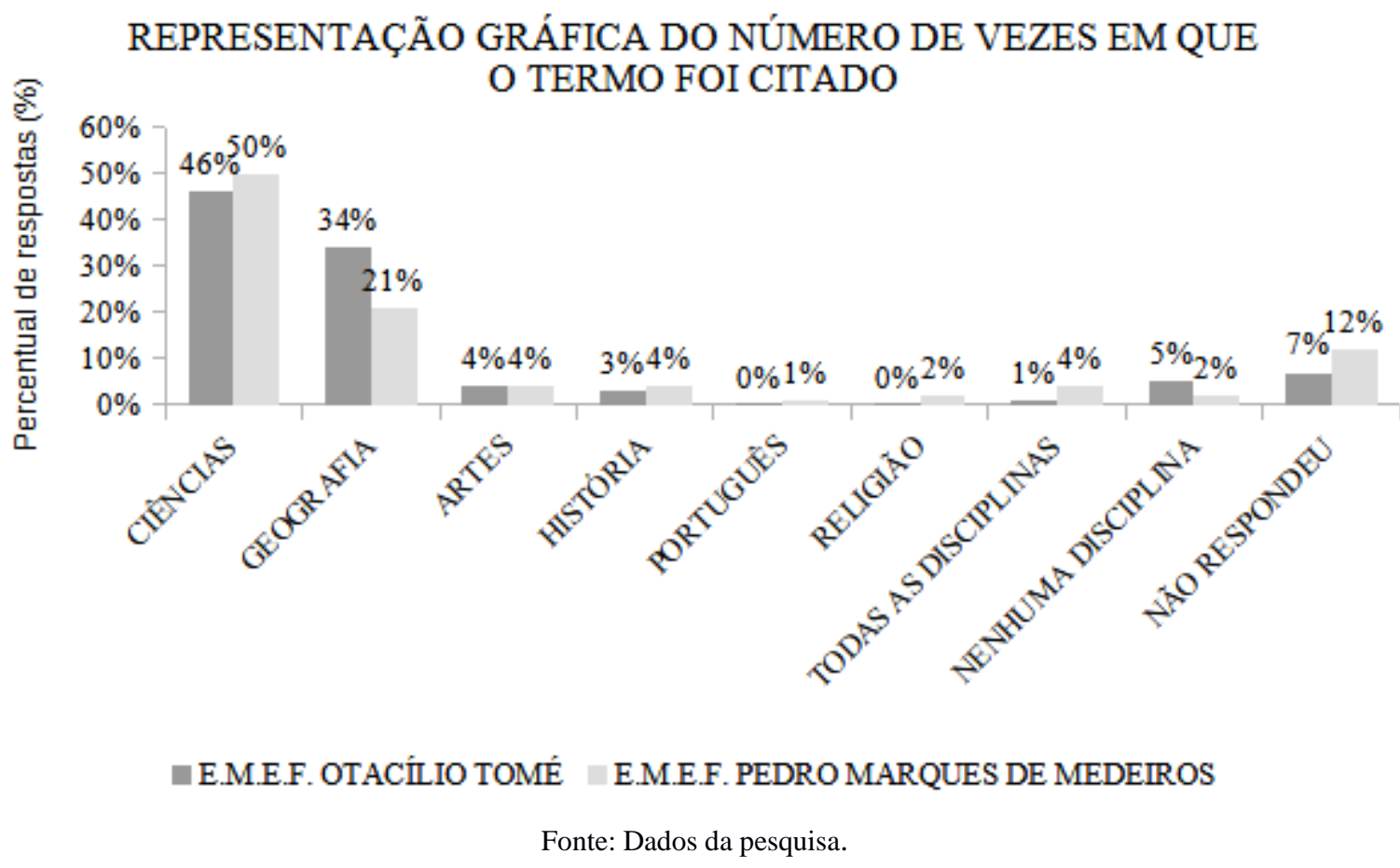

Resultados semelhantes foram encontrados por Gomes, Santos e Aparecida (2018) em uma unidade escolar do ensino fundamental, onde ficou constatado que as disciplinas mais citadas foram Ciências e Geografia, corroborando com este estudo, com isso, os autores ainda destacam que os resultados não são ideais para o ensino uma vez que vão em contra aos Parâmetros Curriculares Nacionais (PCNs) que orienta o desenvolvimento da temática ambiental de forma transversal e interdisciplinar.

Em complementação para a na nona pergunta alguns estudantes citaram quais seriam as atividades ou projetos no qual haviam participado, 28 alunos da EMEFOT e 56 da EMEFPMM citaram. Na EMEFOT o maior índice destaca-se para o termo relatado pelos alunos como "Aula de campo no rio", atingindo 32\% das respostas, já na EMEFPMM o termo mais citado foi “Aula de preservação ambiental", com 25\% das respostas (Gráfico 6). 
Gráfico 6 - Percentual das respostas dos alunos referente à nona pergunta do formulário.

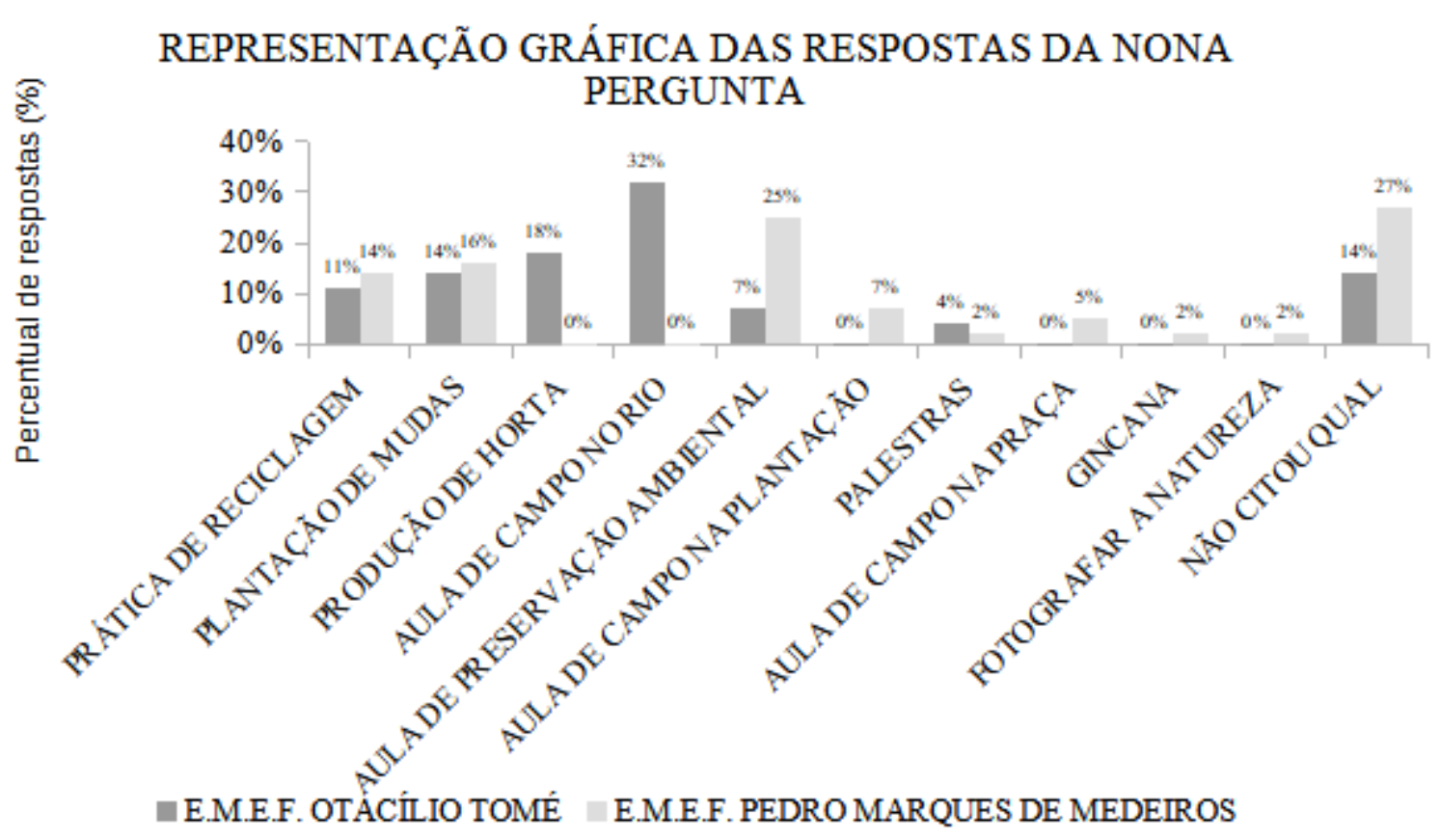

Fonte: Dados da pesquisa.

Muitos alunos da EMEFPM não citaram quais seriam os trabalhos ou projetos com a temática ambiental em sua escola, esse resultado foi observado por Cabral e Nascimento (2020) em duas escolas públicas do ensino fundamental de Goiânia-GO, foi constatado que apenas metade dos alunos afirmaram ter participado, esse dado é preocupante pois essas ações são consideradas de suma importância para conscientização da comunidade em prol da conservação do meio ambiente.

Complementando a décima pergunta, os alunos puderam expor quais seriam os projetos e atividades que são desenvolvidas atualmente nas referidas escolas, 34 alunos da EMEFOT citaram 38 exemplos, 65 estudantes da EMEFPMM citaram 68 ações ou projetos, na EMEFOT o termo "caminhada ecológica” alcançou o maior percentual com 29\%, já na EMEFPMM, o termo "lixo no lixo" foi o que mais se destacou também com $28 \%$. O percentual foi representado pelo número de vezes em que o termo foi citado pelos alunos (Gráfico 7). 
Gráfico 7 - Percentual do número de vezes em que o termo foi citado pelos alunos na décima pergunta.

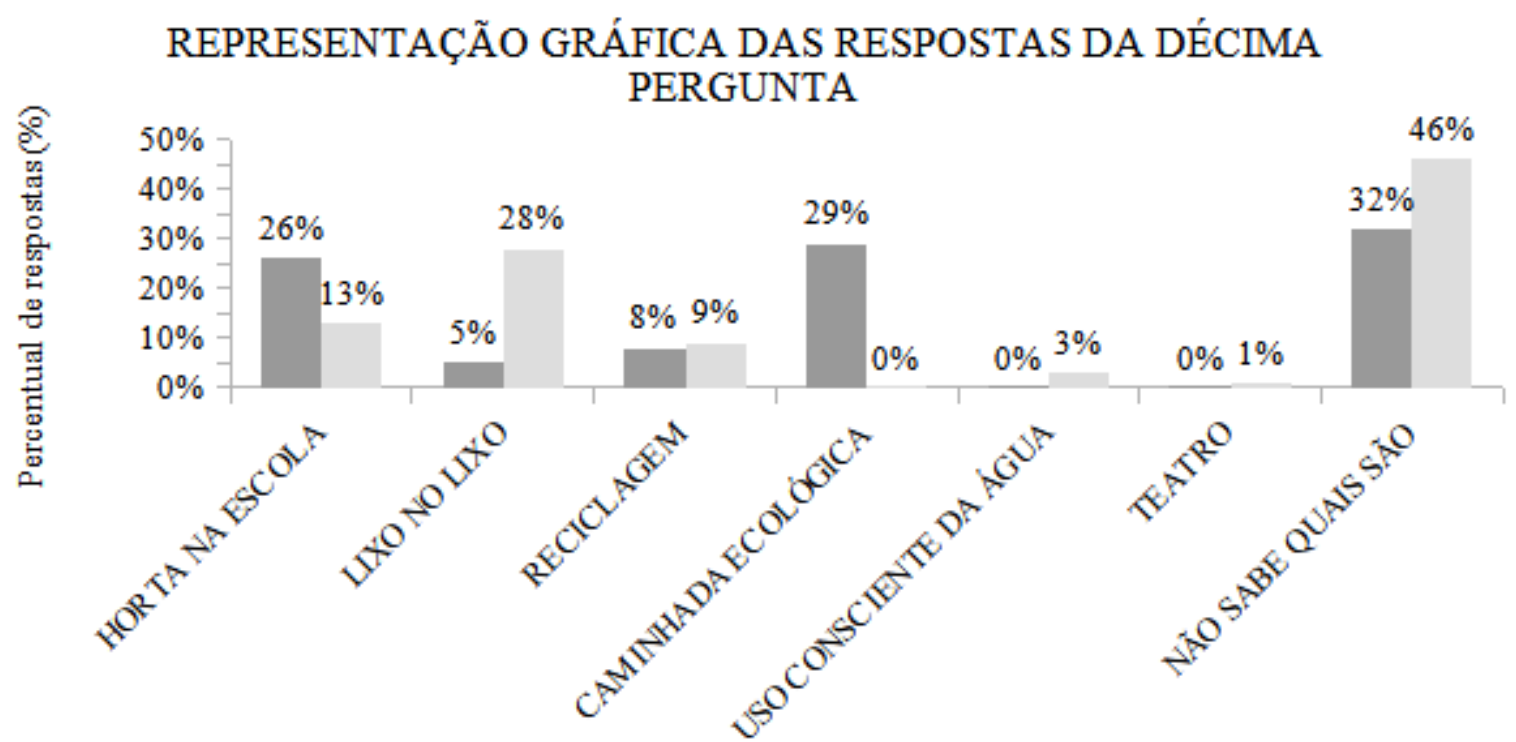

घ.M.E.F. OTACÍLIO TOMÉ $\square$ E.M.E.F. PEDRO MARQUES DE MEDEIROS

Fonte: Dados da pesquisa.

A "caminhada ecológica" citada pelos alunos da EEEFOT induz uma interpretação da natureza junto ao desenvolvimento sustentável e favorece ao aluno a participação de uma prática ligada ao meio ambiente, essa estratégia de aprendizagem favorece um pensamento crítico, fornece informações sobre o uso correto na natureza e instiga o aluno para a valorização e preservação do meio ambiente (Silva, et al., 2012). Conforme os Parâmetros Curriculares Nacionais: meio ambiente (1998) “cabe à escola também garantir situações em que os alunos possam pôr em prática sua capacidade de atuação”.

Sabendo que a Educação Ambiental é uma ferramenta disponível para que a escola seja capaz de proporcionar conscientização e garantir um futuro promissor, é imprescindível a criação de estratégias educacionais contínuas durante todo o ano letivo, ações que impeçam que os alunos sejam levados ao esquecimento e que induza a reflexão de que suas ações no presente gerarão consequências futuras no meio ambiente.

\section{Considerações Finais}

Diante do estudo da identificação da percepção sobre o meio ambiente de alunos dos anos finais do ensino fundamental do município de Paulista-PB, registrou-se que $89 \%$ dos alunos de ambas escolas são conhecedoras da definição do termo sobre o meio ambiente. No entanto, estes alunos não se percebem como integrante do meio ambiente, sendo importante que a escola promova aos alunos experiências práticas e ao seu entorno para ser compreendido que o meio ambiente é uma unidade em que o homem nela está. Esta dificuldade nos surpreende devido as escolas situarem no campo, o que sugeria que havendo um contato maior com o meio natural tenderia a um pertencimento de integração ao meio ambiente.

Ficou evidenciada a necessidade das escolas em desenvolverem e trabalharem a temática ambiental de forma transversal entre as disciplinas do currículo escolar, uma vez em que os alunos evidenciaram uma carência em identificar a participação das temáticas sobre o meio ambiente em muitas disciplinas, contrapondo-se ao que sugerem os Parâmetros Curriculares Nacionais.

Outra evidência constatada neste estudo é a positiva participação das escolas no processo de ações e projetos com a temática ambiental. E isto aconteceu devido ao processo educativo estabelecido em trazer os alunos como protagonistas ativos 
de participação em atividades que envolvem o meio ambiente. Reforçam a importância do ambiente escolar para estimular as práticas de educação ambiental nos currículos que permeie todas as ações pedagógicas e de gestão da escola.

A percepção ambiental é uma alternativa usada para a integração da educação ambiental com intuito de contribuir no equilíbrio natural, as escolas estudadas neste trabalho tem uma importante função para facilitar o processo do desenvolvimento reflexivo através de ações que favoreçam a conscientização, porém, fica evidenciado a necessidade da criação de metodologias contínuas ao longo do ano letivo das ações que serão usadas no intuito de sensibilizar a classe estudantil, podendo assim, no futuro, dispor de adultos com mais chances de contribuir positivamente com a realidade ambiental do planeta.

Assim, este estudo termina apresentando um diagnóstico quanto a percepção da temática de meio ambiente de duas comunidades escolares e que diante destes dados deve embasar ajustes aos processos educativos para a educação ambiental dirigida nas escolas, ainda propõe sugestões para trabalhos futuros de forma que amplie o entendimento da temática meio ambiente. Assim, sugerimos estudos sobre a percepção ambiental da gestão de áreas verdes, sobre o valor atribuído aos espaços do campo e da cidade entre outras temáticas. Pode-se diante do perfil traçado e analisado pelos estudos de percepção ambiental realizar atividades práticas de intervenção relacionadas à Educação Ambiental e pedagógica.

\section{Referências}

Appolinário, F. (2006). Metodologia da ciência: filosofia e prática da pesquisa. Thomson.

Brasil. (1981). Lei n. 6.938, de 31 de agosto de 1981. Dispõe sobre a Política Nacional do Meio Ambiente, seus fins e mecanismos de formulação e aplicação, e dá outras providências. Brasília. 1981. http://www.planalto.gov.br/ccivil_03/leis/16938.htm

Cabral, H. M., \& do Nascimento, G. P. (2020). A percepção ambiental de discentes do ensino fundamental II em escolas públicas de Goiânia (GO). Brazilian Applied Science Review, 4(1), 186-201.

Castoldi, R., Bernardi, R., \& Polinarski, C. A. (2009). Percepção dos problemas ambientais por alunos do ensino médio. Revista Brasileira de Ciência, Tecnologia e Sociedade, 1(1).

Chauí, M. (2002). Experiência do pensamento: ensaios sobre a obra de Merleau-Ponty. Martins Fontes.

Costa, A. C. G. da. (2001) A presença da Pedagogia: teoria e prática da ação socioeducativa. São Paulo: Global/Instituto Ayrton Sena.

Costa, C. C., \& Maroti, P. S. (2009). Expedições Científicas com Alunos de uma Escola Rural: Educação Ambiental em Recursos Hídricos. Educação Ambiental em Ação. n. 29.

Faggionato, S. (2011). Percepção Ambiental. Material e Textos. Disponível em: http://educar.sc.usp.br/biologiatextos//m_a_txt4.html Acesso em: 4 jun. 2021.

França, M. C. (2006). A Educação Ambiental na escola: um estudo sobre as representações sociais dos professores do ensino fundamental do município de Pouso Redondo - SC. Dissertação de Mestrado em Educação. Universidade do Oeste de Santa Catarina.

Gomes, J. N. D., Santos, L. A. D., \& Aparecida, A. (2018). Educação Ambiental na conscientização e preservação do meio ambiente: Unidade Escolar Zezita Sampaio, Buriti dos Lopes, PI. Ambiente \& Educação: Revista de Educação Ambiental, 23(1).

Gonçalves, W. (1999). Florestas urbanas: ação ambiental. Porto Alegre: Ed. Cinco Continentes.

Gregorini, T., \& Missirian, G. L. B. (2009). Percepção ambiental dos alunos do $5^{\circ}$ ano do ensino fundamental, do distrito de Pirapora-MS. REMEA-Revista Eletrônica do Mestrado em Educação Ambiental, 22.

Guimarães, M. (1995). A Dimensão ambiental na educação. Papirus Editora. 6. ed. Campinas: Papirus, (Coleção Magistério: Formação e trabalho pedagógico). IBGE Instituto brasileiro de geografia e estatística. Censo demográfico 2010. Disponível em: https://cidades.ibge.gov.br/ Acesso em 16 de Maio, 2021.

Leff, E. (2010). Epistemologia ambiental. 5. ed. São Paulo: Cortez. 240 p.

Leite, I. A., Leite, C. A., \& Leite, C. A. (2017). Percepção de alunos acerca de educação ambiental em uma comunidade escolar, Patos-PB. Biodiversidade, $16(2)$.

Lima, F. C. (2017). História Ambiental com alunos da Maré e da Ilha do Governador: Perspectivas de estudantes do ensino básico. XII Semana de História Política. Conflitos e resistências: entre práticas, expectativas e rupturas. IX seminário nacional de história política, cultura e sociedade.

Marin, A. A. (2008). Pesquisa em educação ambiental e percepção ambiental. Pesquisa em educação ambiental, 3(1), $203-222$.

Medeiros, A. B., Mendonça, M. J. D. S. L., Sousa, G. L., \& Oliveira, I. P. (2011). A Importância da educação ambiental na escola nas séries iniciais. Revista Faculdade Montes Belos, 4(1). 
Research, Society and Development, v. 10, n. 12, e128101220302, 2021 (CC BY 4.0) | ISSN 2525-3409 | DOI: http://dx.doi.org/10.33448/rsd-v10i12.20302

Medeiros, M. C. S., Ribeiro, M. D. C. M., \& Ferreira, C. M. D. A. (2011). Meio ambiente e educação ambiental nas escolas públicas. Âmbito Jurídico, Rio Grande, XIV, (92), 539-553.

Oliveira, E. M., Santos, W. M. B., Morais, J. L., Bassetti, F., \& Bergamasco, R. (2013). Percepção ambiental e sensibilização de alunos de colégio estadual sobre a preservação de nascente. REMEA-Revista Eletrônica do Mestrado em Educação Ambiental, 30(1), 23-37.

Parâmetros Curriculares Nacionais: meio ambiente (1998). http://portal.mec.gov.br/seb/arquivos/pdf/meioambiente.pdf

Pereira, E. M., Farrapeira, C. M. R., \& de Lyra Pinto, S. (2006). Percepção e educação ambiental sobre manguezais em escolas públicas da região metropolitana do Recife. REMEA-Revista Eletrônica do Mestrado em Educação Ambiental, 17.

Prodanov, C. C., \& De Freitas, E. C. (2013). Metodologia do trabalho científico: métodos e técnicas da pesquisa e do trabalho acadêmico-2a Edição. Editora Feevale.

Santos, A. D., \& Vasconcelos, C. A. D. (2017). Percepção ambiental e mapas mentais: um diagnóstico dos alunos acerca do ecossistema manguezal. Revista REAMEC. v. 5, n. 2, p. 344-359

Silva, M. M., Netto, T. A., de Azevedo, L. F., Scarton, L. P., \& Hillig, C. (2012). Trilha ecológica como prática de educação ambiental. Revista Eletrônica em Gestão, Educação e Tecnologia Ambiental, 5(5), 705-719.

Sousa, M. L. L., \& Fernandes, A. C. (2015). Educação ambiental em pau dos ferros (Rn): em foco a Escola municipal professor Severino bezerra. Revista Brasileira de Educação Ambiental (RevBEA), 10(2), 318-343.

Vasconcelos, F. A. L. (2005). Análise comparativa da percepção ambiental e conhecimento de alunos da rede pública e particular da Região Metropolitana do Grande Recife acerca do tema "Ambientes Recifais”. 2005. 70 f. Monografia (Bacharelado em Ciências Biológicas) - Universidade Federal Rural de Pernambuco, Recife.

Viégas, A., \& Guimarães, M. (2004). Crianças e educação ambiental na escola: associação necessária para um mundo melhor. Revista brasileira de educação ambiental, Brasília, n. 0, 56-62.

Wollmann, E. M., \& Braibante, M. E. F. (2013). A Educação ambiental no nível médio e as percepções dos estudantes sobre meio ambiente. Atas do IX Encontro Nacional de Pesquisa em Educação em Ciências - IX ENPEC. 